\title{
Del contrato fijo de obra al contrato indefinido adscrito a obra. Un cambio meramente estético a efectos estadísticos
}

\author{
The impact of the reform in the construction sector. \\ A merely aesthetic change for statistical purposes
}

\author{
Cristina Aragón Gómez \\ Profesora de Derecho del Trabajo y de la Seguridad Social \\ Universidad Nacional de Educación a Distancia (UNED) \\ ORCID ID: 0000-0001-6177-8287
}

doi: https://doi.org/10.20318/labos.2022.6638

Resumen: El Real Decreto Ley 32/2021 deroga, con efectos del día 30-3-2022, el contrato por obra o servicio determinado. $Y$ esta decisión legislativa tiene un claro impacto en el sector de la construcción, en el que el contrato por obra es la modalidad contractual más empleada. Los datos así lo corroboran: según las estadísticas del SEPE correspondientes a 2021, del 100\% de los contratos que se suscribieron a lo largo del año, cerca del $75 \%$ revestía esta concreta modalidad. Pero la posibilidad de acudir a este tipo de contrato desaparece con motivo de la reforma. En contrapartida, el legislador prevé un régimen particularizado de extinción contractual aplicable a aquellos trabajadores indefinidos que se encuentren adscritos a obra. El objeto del presente artículo se centra, precisamente, en analizar el régimen jurídico de este contrato indefinido adscrito a obra. Pero, para entender el alcance de la reforma y su concreto impacto en el sector de la construcción, resulta necesario entender el punto del que partimos. Y de ahí que, con carácter previo, nos detengamos en el estudio del contrato fijo de obra, en sus orígenes y en su regulación convencional.

Palabras clave: Real Decreto Ley 32/2021, contrato por obra o servicio determinado, temporalidad, sector de la construcción, contrato indefinido adscrito a obra.

Abstract: $\quad$ Royal Decree Law 32/2021 repeals, with effect from 30-3-2022, the contract for a specific work or service. And this legislative decision has a clear impact on the construction sector, in which the contract by work is the most used contractual modality. The data corroborates this: according to the SEPE statistics corresponding to 2021 , of $100 \%$ of the contracts that were signed throughout the year, about $75 \%$ had this specific modality. But the possibility of resorting to this type of contract disappears due to the reform. On the other hand, the legislator provides for a particular regime of contractual termination applicable to those permanent workers who are assigned to work. The purpose of this article focuses precisely on analyzing the legal regime of this indefinite contract assigned to work. But, to understand the scope of the reform and its concrete impact on the construction sector, it is necessary to understand the starting 
point. And hence, previously, we stop at the study of the fixed work contract, its origins and its conventional regulation.

Keywords: $\quad$ Labor reform, Royal Decree Law 32/2021, contract for specific work or service, temporality, construction sector.

\section{Introducción}

El Real Decreto Ley 32/2021 ${ }^{1}$ deroga, con efectos del día 30-3-2022, el contrato por obra o servicio determinado. Y es evidente que esta decisión legislativa tiene un claro impacto en determinados sectores, como es el sector de la construcción. Como sabemos, el contrato por obra o servicio era el que se concertaba para la realización de una obra o la prestación de un servicio determinado, con autonomía y sustantividad propia dentro de la actividad de la empresa y cuya ejecución, aunque limitada en el tiempo, era en principio de duración incierta. De acuerdo a lo expuesto, constituía una modalidad contractual que se caracterizaba por esa doble delimitación tanto espacial, como temporal. El objeto del contrato para obra o servicio determinado se encontraba acotado en el espacio, en la medida en que suponía una tarea individualizable, separable de la actividad de la empresa ${ }^{2}$. Por otro lado, constituía una actividad también limitada en el tiempo, pues se consumía con su total ejecución ${ }^{3}$; era una actividad llamada a ser concluida, que se definía por tener un principio y por tener un término. Además, la obra o el servicio no tenían por qué ser actividades excepcionales de la empresa, sino que podían suponer actividades normales de la misma ${ }^{4}$, pues esa normalidad, en palabras del propio Tribunal Supremo, no alteraba el carácter temporal de la necesidad de trabajo5.

Precisamente por ello, se entendió que estábamos ante el contrato típico del sector de la construcción: cada una de las obras que ejecutaba la empresa era distinta y autónoma de las demás (por lo que cumplía el primer requisito de delimitación espacial) y estaba llamada a ser concluida (por lo que reunía también el segundo requisito de acotación en el tiempo). De hecho, el contrato por obra fue definido por la doctrina como la modalidad contractual natural del sector, como la modalidad contractual propia de la construcción. Y los datos lo corroboran: Durante el año 2021, la tasa de temporalidad en el sector ha sido próxima al $35 \%{ }^{6}$. Y según las estadísticas del SEPE, del $100 \%$ de los contratos que se suscribieron a lo largo del año, el 73,49\% revestía esta concreta modalidad ${ }^{7}$.

La DA3 ${ }^{a}$ ET y la DA $3^{\text {a }}$ Ley 32/2006, de 18 de octubre, reguladora de la subcontratación en el sector de la construcción ${ }^{8}$ (en adelante, LSC) otorgaban a la negociación colectiva la facultad de adaptar al sector de la construcción el contrato de obra o servicio determinado, regulado con carácter general del art. 15 ET. Y, a tal efecto, el convenio colectivo sectorial de ámbito estatal regulaba -sigue regulando- el contrato fijo de obra, que no es sino una concreción del contrato por obra o servicio determinado. El contrato fijo de obra constituye una modalidad contractual

${ }^{1}$ Real Decreto-ley 32/2021, de 28 de diciembre, de medidas urgentes para la reforma laboral, la garantía de la estabilidad en el empleo y la transformación del mercado de trabajo (BOE 30-12-2021, núm. 313).

${ }^{2}$ STSJ Cantabria 8-08-2001, Ro 698/2001.

${ }^{3}$ GARCÍA NINET, José Ignacio; VICENTE PALACIO, Ma. Arántzazu. Contrato temporal para obra o servicio determinado: nueva legislación y jurisprudencia. Valencia: Tirant lo Blanch, 1998, p. 41; ALZAGA RUÍZ, Icíar. Contratación laboral temporal: Un estudio jurisprudencial. Madrid: Edersa, 2000, p. 21.

${ }^{4}$ Ídem.

${ }^{5}$ STS 6-10-2006, Ro 4243/2005.

${ }^{6}$ INE. Encuesta de Población Activa. "Ocupados por tipo de contrato o relación laboral de los asalariados, sexo y sector económico". Media de los cuatro trimestres del año 2021.

SEPE. Estadísticas de contratos. "Contratos de trabajo según tipo de contrato por sector, sección y división de actividad económica”. Datos acumulados a diciembre de 2021.

${ }^{8}$ BOE 19-10-2006, núm. 250. 
que encuentra su origen en la Orden de 28-8-1970 por la que se aprobó la Ordenanza de Trabajo de la Construcción, Vidrio y Cerámica ${ }^{9}$ y que representa -en palabras del Tribunal Supremo- una antigua y pacífica práctica contractual ${ }^{10}$, que se ha mantenido (aunque con cambios muy significativos, como veremos) en la regulación convencional hasta la actualidad. En definitiva, "el contrato para obra o servicio determinado del Estatuto de los Trabajadores, es el contrato fijo de obra del convenio colectivo de la construcción"1.

Pues bien, la posibilidad de acudir a este contrato fijo de obra desaparece con motivo de la reforma de 2021. En contrapartida, el legislador prevé un régimen particularizado de extinción contractual aplicable a aquellos trabajadores indefinidos que se encuentren adscritos a obra. El objeto del presente artículo se centra, precisamente, en analizar el régimen jurídico de este contrato indefinido adscrito a obra. Pero, para entender el alcance de la reforma y su concreto impacto en el sector de la construcción, resulta necesario entender el punto del que partimos. De ahí que, con carácter previo, nos detengamos en el estudio del contrato fijo de obra, en sus orígenes y en su regulación convencional.

\section{El punto de partida: El contrato fijo de obra en el sector de la construcción}

\subsection{Los origenes del contrato fijo de obra}

La antigua Ordenanza de Trabajo del sector de la construcción ya definía el contrato para trabajo fijo en obra en su art. 42, como un contrato exclusivo de este concreto sector de actividad. En el capítulo IV, dedicado a las modalidades contractuales, la Ordenanza distinguía cuatro tipos de contrato de trabajo diferentes: a) el contrato eventual, que era aquel que se concertaba para la prestación de servicios o para la ejecución de obras por una duración máxima de 120 días $^{12}$; b) el contrato de interinidad, que tenía por objeto la sustitución de trabajadores de plantilla durante sus ausencias obligadas; c) el contrato para el personal fijo o de plantilla, que estaba previsto para dos supuestos diferentes: $1^{\circ}$ ) cuando el objeto del contrato fuese la realización de la actividad normal de la empresa, cuya duración no se encontrase condicionada por la duración de la obra en la que el trabajador prestara servicios [art. $43 \mathrm{a}$ ), b) y c)]; $2^{\circ}$ ) cuando el contrato de trabajo, habiendo nacido temporal, se hubiese prolongado por un determinado período de tiempo [art. $43 \mathrm{~d}$ ) y e)]; y, finalmente, d) el contrato para el personal fijo en obra determinada, que se definía como aquel que tenía por objeto la realización de una obra o servicio determinado y que se había prolongado por un lapso de tiempo superior a 120 días (pues, en caso contrario, si no alcanzaba este período de duración, era calificado como contrato eventual, tal y como ya hemos visto).

Pues bien, dentro de esta última modalidad contractual, la Ordenanza distinguía dos supuestos: a) el personal fijo en obra que prestaba servicios en distintos centros de trabajo de la empresa; y b) el personal fijo en obra que trabajaba en una única obra de larga duración. Y es importante realizar esta distinción por cuanto el régimen jurídico previsto difería en uno y otro caso.

a) En el primer supuesto - cuando el trabajador había prestado servicios en diferentes centros de trabajo-, el contrato se convertía en indefinido por el mero transcurso de un concreto período de tiempo. Según lo previsto en el art. 43.e) de la Ordenanza, adquiría la condi-

\footnotetext{
${ }^{9}$ BOE 7-9-1970, núm. 214.

${ }^{10}$ STS 30-6-2005, Ro 2426/2004.

${ }^{11}$ STSJ Madrid 31-3-2003, Ro 685/2003.

${ }^{12}$ Duración que se redujo poco tiempo después a 15 días, con motivo de la reforma llevada a cabo por la Orden 27-07-1973 (BOE 31-07-1973, núm. 182).
} 
ción de personal de plantilla, el trabajador fijo en obra que hubiese prestado servicios para la empresa durante dos ańos consecutivos.

b) En el segundo supuesto -cuando el trabajador había prestado servicios en un único centro de trabajo- el empleado no adquiría la condición de fijo por el cumplimiento del plazo mencionado; si bien, transcurrido el mismo, pasaba a disfrutar de los beneficios económicos de los fijos de plantilla. En este caso, el contrato no se convertía en indefinido sino cuando concurrían dos condiciones adicionales: que finalizara la obra de larga duración a la que se encontraba adscrito el trabajador y que éste otorgara su conformidad. Así es, finalizada la obra de larga duración, los trabajadores con más de dos años al servicio de la empresa en dicho centro tenían la posibilidad de optar entre incorporarse definitivamente a la plantilla (adquiriendo, por tanto, la condición de fijo) o cesar en la misma, en cuyo caso tenían derecho a la indemnización expresamente prevista en el art. 44.c) Ordenanza y que suponía un 4,5\% sobre el salario devengado en jornada ordinaria durante el tiempo de prestación de servicios. Ahora bien, este derecho de opción se encontraba condicionado a que la empresa tuviera otras obras en las que reubicar al trabajador (con independencia de cuál fuera la localidad en la que se encontraran) y a que tuviese plaza vacante en las mismas.

\subsection{La regulación convencional del contrato fijo de obra y su evolución}

\subsubsection{El contrato fijo de obra. Una denominación que lleva a equívocos}

El VI Convenio General del Sector de la Construcción (en adelante, CGSC) diferencia entre el contrato fijo de plantilla y el contrato fijo de obra. El primero se define por su carácter indefinido. El segundo, a pesar de su nombre, tiene carácter temporal ${ }^{13}$, pues concluye cuando finalice la obra; más concretamente, cuando finalizan los trabajos del oficio del empleado en dicha obra. Es más, la regulación convencional prevé la posibilidad de que el cese de los trabajadores, miembros de una misma unidad de obra, se vaya produciendo de forma paulatina conforme vaya disminuyendo el volumen de actividad (art. 24.6 VI CGSC). De esta manera se ha considerado ajustado a derecho que la empresa vaya extinguiendo los contratos de trabajo a medida que la obra vaya concluyendo y las necesidades de personal igualmente decrezcan ${ }^{14}$. Y ello con independencia de cuál sea el tiempo por el que esta obra se haya prolongado.

Ahora bien, el convenio no solo denomina fijo a un contrato temporal, sino que también denomina contrato de obra (en singular) a lo que puede convertirse en un contrato de obras (en plural), por cuanto el mismo empleado puede ser destinado a diferentes centros de trabajo de la misma empresa. Y nos enfrentamos, en ello, a una segunda contradicción. Según el artículo 24.3, el personal fijo de obra puede prestar servicios a una misma empresa y en distintos centros de trabajo de una misma provincia siempre que exista acuerdo expreso para cada uno de los distintos centros sucesivos, durante un período máximo de tres ańos consecutivos, salvo que los trabajos de su especialidad en la última obra se prolonguen más allá de dicho término. Por lo expuesto, la posible adscripción del trabajador a varias obras no tiene carácter ilimitado, sino que se condiciona al cumplimiento de determinados requisitos: a) que la sucesión de obras no se prolongue de forma

\footnotetext{
${ }^{13}$ Ver en este sentido las reflexiones de LAHERA FORTEZA, Jesús. El papel del convenio colectivo en el contrato de obra. Revista de la Facultad de Derecho de la Universidad Complutense, 1999, núm. 24, p. 72.

${ }_{14}$ STSJ Cataluña 4-11- 2005, Ro 3954/2004; STSJ Madrid 5-2-2007, Ro 9/2007 y STSJ Islas Canarias 27-2-2007, Ro $1534 / 2007$.
} 
indefinida; b) que el cambio de centro no derive de la voluntad unilateral del empresario, pues es necesario que exista el acuerdo expreso de ambas partes para la adscripción del trabajador a cada uno de los distintos centros sucesivos; y c) que los distintos centros de trabajo se encuentren en una misma provincia.

Pues bien, ¿por cuánto tiempo se puede prolongar esta concatenación de obras? Dependerá de la duración de la última obra, es decir, de la que se estuviese ejecutando en el momento de traspasar el umbral temporal mencionado, pues este período de tres ańos ya no opera como máximo ${ }^{15}$ y tiene un alcance limitado, en la medida en que constituye un requisito necesario pero, en ningún caso, suficiente.

De otro lado, la regulación convencional prevé una indemnización por cese que asciende al $7 \%$, calculada sobre los conceptos salariales devengados durante la vigencia del contrato. Si traducimos esta fórmula a los términos a los que estamos acostumbrados los laboralistas, supondría abonar 25,55 días de salario por año de servicio.

\subsubsection{Particularidades del contrato fijo de obra en la regulación convencional}

De acuerdo a la regulación del contrato fijo de obra que preveía la antigua Ordenanza de la construcción, el empresario podía encomendar al trabajador, finalizada una obra, funciones en una nueva sin que por ello el contrato se prorrogara necesariamente de forma indefinida. Ahora bien, transcurrido un período de dos ańos, el trabajador que hubiese prestado servicios para una misma empresa y en diferentes centros de trabajo, adquiría automáticamente la condición de fijo de plantilla.

La posterior regulación convencional amplió el lapso de tiempo que había de transcurrir para que el trabajador se convirtiera en indefinido. Según lo previsto en el art. 29 CGSC para los años 1992-1996 ${ }^{16}$, el trabajador podía prestar servicios en distintos centros de trabajo de una misma provincia durante un período máximo de tres años. Cumplido dicho período, si no había mediado comunicación escrita del cese, el trabajador adquiriría la condición de fijo de plantilla.

Pero el CGSC 2002-2006 ${ }^{17}$ introdujo una importante salvedad (que se ha mantenido en idénticos términos hasta la actualidad). En su virtud, el personal fijo de obra podía prestar servicios en distintos centros de trabajo durante un período máximo de tres años consecutivos, salvo que los trabajos de su especialidad en la última obra se prolongaran más allá de dicho término. El alcance de esta advertencia es obvio. En aplicación de la regulación originaria, transcurridos los tres años, el trabajador adquiría la condición de fijo de plantilla sin más condicionamientos. En base al régimen actual, es necesario que concurra un requisito adicional para que se produzca esa conversión del contrato. En definitiva, han de concurrir las siguientes condiciones: Primera, que el trabajador lleve prestando servicios en la empresa por un período de, al menos, tres ańos. Segunda, que finalizada la obra que se estaba ejecutando cuando se traspasó este umbral de los tres años, la empresa no denuncie el contrato de trabajo y encomiende al empleado funciones en una obra diferente. Sólo entonces el trabajador adquiría la condición de fijo.

Además, es importante destacar que este período de tiempo no opera, ni siquiera, como mínimo. A diferencia de la regulación establecida en la antigua ordenanza de la construcción, el CGSC no impone al empresario la obligación de reubicar al trabajador en otro centro de trabajo, aun cuando existan nuevas obras y haya vacante en las mismas. El límite previsto en el convenio

${ }^{15}$ DOCTOR SÁNCHEZ-MIGALLÓN, Rubén. El contrato fijo de obra en el sector de la construcción. Revista General de Derecho del Trabajo y de la Seguridad Social, 2005, núm. 9, p. 5.

${ }^{16}$ BOE 20-5-1992, núm. 121.

${ }^{17}$ BOE 10-8-2002, núm. 191. 
colectivo, no supone en ningún caso que tales contratos deban necesariamente prorrogarse hasta agotar el período los tres años ${ }^{18}$.

\subsubsection{La huida de los negociadores para impedir la aplicación de la regulación legal}

Con el objeto de fomentar el empleo estable, la Ley $43 / 2006^{19}$ limitó la concatenación de contratos temporales, aun cuando estos fueran plenamente lícitos. Concretamente, exigió cuatro requisitos para que operara la conversión del contrato en indefinido con motivo de la concatenación: Primero, que se produjera una sucesión de contratos temporales ("dos o más contratos temporales"). Segundo, que esa sucesión tuviera lugar entre un mismo trabajador y una misma empresa, con independencia de que la contratación fuese directa o indirecta, a través de una empresa de trabajo temporal. Tercero, que fuera para cubrir un mismo puesto de trabajo. Y cuarto y último, que la acumulación de los diferentes períodos contratados superara un determinado plazo (veinticuatro meses en un período de treinta).

Pues bien, el IV CGSC ${ }^{20}$, el correspondiente a los ańos 2007-2011 (acordado con posterioridad a la Ley 43/2006) introdujo en la regulación del contrato fijo de obra un matiz que perseguía un propósito claro: eludir la aplicación del 15.5 ET. Conforme a la redacción del convenio, el trabajador podía prestar servicios en diferentes centros de trabajo, pero en todo caso se mantendría "el carácter de un único contrato". De esta forma, si estábamos ante un único contrato, la regla prevista en el art. 15.5 ET devenía inoperante, pues la reforma de 2006 no estableció un plazo máximo de contratación temporal, sino un plazo máximo de contratación sucesiva temporal ${ }^{21}$.

No obstante, la afirmación del convenio resultaba controvertida, pues en puridad no estábamos ante un único contrato cuyo objeto se iba novando para amparar la ejecución de varias obras, sino ante varios contratos de trabajo por obra que se tramitaban como uno solo, añadiendo un anexo por cada cambio. Así lo entendió tanto la Inspección de Trabajo y Seguridad Social (en relación a si había que cotizar o no por las dietas) ${ }^{22}$, como la Dirección General de Tributos (con respecto a la tributación de los gastos de desplazamiento y manutención) ${ }^{23}$ o como el propio Tribunal Supremo en su sentencia de 30-6-2005, Ro 2426/2004, de acuerdo a la cual la regulación del contrato fijo de obra lo que trataba era de evitar las cargas burocráticas que supondría la formalización de sucesivos contratos con un mismo trabajador, por lo que bastaba con añadir el anexo en el que se variara su objeto. En opinión de la doctrina más solvente, si estábamos ante un único contrato y no ante una

${ }^{18}$ STSJ Extremadura 14-07-1993; STSJ Madrid 22-03-2002, Ro 711/2002.

${ }^{19}$ Ley 43/2006, de 29 de diciembre, para la mejora del crecimiento y del empleo (BOE 30-12-2006, núm. 312).

${ }^{20}$ BOE 17-8-2007, núm. 197.

${ }^{21}$ GORELLI HERNÁNDEZ, Juan. La reforma laboral 2006 y la contratación temporal: la lucha contra el abuso en la contratación temporal. Un análisis de urgencia. Actualidad Laboral, 2006, núm. 17. VALVERDE ASENSIO, Antonio J. La reforma del RDL 5/2006: el nuevo art. 15.5 del Estatuto de los Trabajadores y la limitación a la sucesión de contratos temporales. Iuslabor, 2006, núm. 3, p. 3.

${ }^{22}$ En el criterio técnico de la Inspección de Trabajo 40/2005, de 18-1-2005, sobre cotización por dietas y gastos de desplazamiento en el sector de la construcción de los trabajadores fijos de obra, la propia Inspección de Trabajo consideró que estábamos ante diferentes contratos, cada uno de ellos adscrito a un centro de trabajo diferente. Precisamente por ello, entendió que la adscripción del trabajador a una nueva obra no suponía un desplazamiento (al no producirse un cambio con respecto al lugar habitual de trabajo, sino que el centro habitual era precisamente aquel para el que el trabajador haya sido contratado). En consecuencia, las dietas abonadas por la empresa, conforme a lo previsto en el convenio colectivo, debían computarse en la base de cotización a la Seguridad Social.

${ }^{23}$ En efecto, en las Consultas Vinculantes de 13-8-2007, núm. V1777-07, 22-12-2008, núm. V2468-08 y 13-9-2018, núm. V2493-18, la Dirección General de Tributos entiende que el destino del trabajador en el centro de trabajo donde en concreto se ubica la obra o el servicio, invalida la aplicación del régimen de dietas, por cuanto se consideraría que las cantidades que se abonasen lo serían para compensar los desplazamientos desde el domicilio particular a los centros de trabajo a los que esté destinado el trabajador, lo cual conllevaría a que estuvieran sometidos a tributación en su totalidad. 
sucesión de contratos que se tramitaban como uno solo, el contrato fijo de obra podría estar rompiendo de forma implícita el principio de causalidad en la contratación temporal ${ }^{24}$.

Además, el IV CGSC se preocupó por definir qué se entendía por "puesto de trabajo" en el sector de la construcción. Conforme a esta nueva definición, el concepto puesto de trabajo venía determinado por la conjunción de diferentes factores: a) las funciones que desempeñaba el trabajador; b) su categoría profesional; y c) el centro de trabajo donde prestaba servicios (art. 18). Y mediante esta delimitación convencional igualmente se trataba de impedir la aplicación del art. 15.5 ET, pues la mera adscripción del trabajador a una nueva obra suponía prestar servicios en un nuevo centro de trabajo y, en consecuencia, se ocupaba un nuevo puesto, por lo que no se cumplía otra de las exigencias previstas en el precepto estatutario.

Es cierto que según la DA. 3a LSC, la negociación colectiva de ámbito estatal podía adaptar al sector de la construcción la modalidad del contrato por obra o servicio determinado prevista con carácter general, "en términos análogos a los actualmente regulados en dicho ámbito de negociación". Y podía entenderse que esta disposición adicional estaba legalizando el contrato fijo de obra ${ }^{25}$. Pero no podemos perder de vista cuál era el objetivo de esa habilitación legal: esta adaptación debía realizarse con el fin de mejorar la calidad en el empleo y de favorecer la estabilidad laboral. En efecto, uno de los objetivos de la LSC y de su reglamento de desarrollo ${ }^{26}$, era favorecer la calidad en el empleo en este concreto sector de actividad. Y con tal propósito el legislador introdujo determinadas medidas: En primer lugar, el legislador impuso a las empresas cuya actividad consistía en ser contratadas o subcontratadas habitualmente para la realización de trabajos en obras del sector de la construcción, la obligación de contar con un determinado porcentaje de trabajadores indefinidos (art. 4.4 LSC). En segundo lugar, instó a los agentes sociales a que adaptaran la modalidad contractual del contrato por obra o servicio determinado prevista con carácter general, mediante fórmulas que garantizaran una mayor estabilidad en el empleo de los trabajadores que concurren en las obras de construcción (DA 3 ${ }^{\mathrm{a}} \mathrm{LSC}$ ). Y difícilmente podía cumplirse semejante propósito permitiendo que la regulación especial para el sector de la construcción fuese más regresiva que la regulación general.

Sin embargo, el propio Tribunal Supremo admitió sin ambages la regulación convencional del contrato fijo de obra. En palabras de la sentencia de 25-5-2011, Ro 1907/2010: "Ha sido el legislador el que ha confiado a la negociación colectiva, atendiendo a las peculiaridades de cada actividady a las características del puesto de trabajo, el establecimiento de los requisitos necesarios. Esa misma negociación colectiva es la que ha completado la noción de puesto de trabajo a los efectos de lo que se entiende por cambio del mismo". Y no se trata, además, de una resolución aislada, pues este mismo criterio se mantuvo en varias sentencias dictadas con posterioridad ${ }^{27}$, aunque es importante advertir que

\footnotetext{
${ }^{24}$ CRUZ VILLALÓN, Jesús. La nueva regulación de la subcontratación en el sector de la construcción. Boletín Informativo del Consejo Andaluz de Relaciones Laborales, 2006, núm. 6.

${ }^{25}$ Para LUJÁN ALCARÁZ, José. "El contrato fijo de obra del sector de la construcción en la reforma de 2010", Revista Doctrinal Aranzadi Social, 2010, núm. 12, la DA 3a LSC venía a admitir la regulación convencional [aun cuando ésta contrariaba lo dispuesto en el Estatuto]; si bien, la concreción técnica de la voluntad legislativa dejaba mucho que desear. Y, en este mismo sentido, se pronuncia RODRIGO SANBARTOLOMÉ, Francisco Agustín. "El contrato fijo de obra, el artículo 15.5 del ET y las reformas laborales". Estudios financieros. Revista de Trabajo y Seguridad Social: Comentarios, casos prácticos, recursos humanos, 2015, núm. 382, p. 113. Para este autor, el legislador habría legalizado expresamente la regulación convencional, por lo que no existiría colisión entre ésta y el art. 15 ET, dado que la DA. 3a LSC se encuentra contenida en una norma especial para el sector de la construcción, también con rango de ley, y de fecha posterior a la norma que introdujo inicialmente tal limitación en el art. 15.5 ET.

${ }^{26}$ Real Decreto 1109/2007, de 24 de agosto, por el que se desarrolla la Ley 32/2006, de 18 de octubre, reguladora de la subcontratación en el Sector de la Construcción (BOE 25-8-2007, núm. 204).

${ }^{27}$ SSTS 15-6-2011, Ro 2005/2010, 19-7-2011, Ro 1961/2010 y 30-4-2013, Ro 1442/2012, de acuerdo a las cuales, la concatenación no se habría producido en la medida en que el cambio de centro de trabajo impide entender que estemos ante un mismo puesto de trabajo, a la luz de la definición efectuada por el convenio colectivo (tanto el estatal, como el provincial).
} 
no todos los magistrados sostenían el mismo parecer (y varias de esas resoluciones contaron con un voto particular en contra) ${ }^{28}$.

Posteriormente, con la reforma llevada a cabo por la Ley 35/201029, el legislador trató de reducir la dualidad de nuestro mercado laboral, impulsando la creación de empleo estable y de calidad. Y, a tal efecto, introdujo varios cambios en materia de contratación temporal ${ }^{30}$. De un lado, el art. 1.Uno Ley 35/2010 modificó el art. 15.1.a) ET y, en virtud de este cambio, el contrato por obra o servicio determinado no podía tener una duración superior a tres años. Un período que podía ampliarse hasta doce meses más por convenio colectivo de ámbito sectorial estatal o, en su defecto, por convenio colectivo sectorial de ámbito inferior. De forma que, transcurrido este período de tiempo, el trabajador adquiría la condición de fijo de la empresa.

De otro lado, y sin modificar sustancialmente la regulación anterior, la reforma mejoró algunos aspectos del art. 15.5 ET. Así, permitió que la limitación al encadenamiento de contratos temporales se aplicara no solo cuando los contratos se sucediesen en los mismos puestos de trabajo y en la misma empresa (regulación anterior), sino también en puestos de trabajo diferentes y en el mismo grupo de empresas. Además, declaró expresamente que este mecanismo también se aplicaría en supuestos de subrogación empresarial.

Y ante este cambio legislativo, el V CGSC ${ }^{31}$ (correspondiente a los años 2012-2016) incorpora nuevos mecanismos de huida para impedir la aplicación del Estatuto. En primer lugar, el convenio aclara que el contrato fijo de obra se extinguirá cuando concluyan los trabajos del oficio y categoría del trabajador en dicha obra, con independencia de cuál sea su duración, por lo que "no será de aplicación lo establecido en el párrafo primero del art. 15.1.a) del ET". Y, además, añade: "la contratación, con o sin solución de continuidad, para diferente puesto de trabajo mediante dos o más contratos fijos de obra con la misma empresa o grupo de empresas en el periodo y durante el plazo establecido en el art. 15.5 ET, no comportará la adquisición de la condición establecida en dicho precepto".

Y esta exclusión ha sido admitida, sin objeciones, por parte de la doctrina judicial ${ }^{32}$. Y es que ciertamente, la DA $1^{\text {a }}$ Ley 35/2010 -alejándose de forma sustancial de la previsión originalmente contenida en la DA $1^{\text {a }}$ RDLey $10 / 2010^{33}$ y como resultado de la asunción de la enmienda 287 pre-

${ }^{28}$ En efecto, frente a la STS 25-5-2011, Ro 1907/2010, Doña María Lourdes Arastey Sahún formuló voto particular en contra. Para esta magistrada, las remisiones del legislador a la negociación colectiva se ceñían a dos aspectos concretos: a) la identificación de trabajos o tareas con sustantividad propia dentro de la actividad normal de la empresa que pueden cubrirse con contratos de esta naturaleza; y b) la exigencia de determinados requisitos para prevenir la utilización abusiva de contratos de duración determinada con distintos trabajadores para desempeñar el mismo puesto de trabajo cubierto anteriormente con contratos de ese carácter, con o sin solución de continuidad. Por lo tanto, en opinión de la magistrada -que comparto- "no es la definición de puesto de trabajo lo que puede servir para delimitar el campo de la contratación temporal más allá de lo que han fijado las disposiciones de rango legal". Por su parte, frente a la STS 15-6-2011, Ro 2005/2010, el magistrado Don Luis Fernando de Castro Fernández formuló un interesante voto particular en contra, en el que defendió que la habilitación concedida a la negociación colectiva por el legislador no era para excepcionar o limitar la aplicación del art. 15.5 ET, sino muy contrariamente para adoptar las previsiones que fueran necesarias en orden a evitar la utilización abusiva de la contratación temporal. En su opinión, el convenio colectivo se estaría extralimitando y vulneraría claramente la finalidad de la Ley 43/2006, pues impediría aplicar la ley en el sector de la construcción.

${ }^{29}$ Ley 35/2010, de 17 de septiembre, de medidas urgentes para la reforma del mercado de trabajo (BOE 18-9-2010, núm. 227).

${ }^{30}$ In extenso: GOERLICH PESET, José María. "La reforma de la contratación temporal en el Real Decreto-Ley 10/2010". En: GARCÍA-PERROTE ESTARTÍN, Ignacio y MERCADER UGUINA, Jesús R. (dirs). La reforma laboral 2010. Aspectos prácticos. Valladolid: Lex Nova, 2010, pp. 45 a 57.

${ }^{31}$ BOE 15-3-2012, núm. 64.

${ }^{32}$ STSJ Madrid 7-6-2019, Ro 105/2019.

${ }^{33}$ Real Decreto-ley 10/2010, de 16 de junio, de medidas urgentes para la reforma del mercado de trabajo (BOE 17-6-2010, núm. 147). De acuerdo con su redacción originaria, la DA 1a establecía: "1. Lo dispuesto en el artículo 15, apartado 1.a), del Estatuto de los Trabajadores, según la redacción dada al mismo por este real decreto-ley, se entiende sin perjuicio de lo establecido actualmente en la negociación colectiva de ámbito estatal para adaptar la modalidad contractual del contrato de obra o servicio determinado mediante fórmulas que garanticen mayor estabilidad en el empleo de los trabajadores.

2. Igualmente se entiende sin perjuicio de lo que se establezca en la negociación colectiva de conformidad con la disposición adicional tercera de la Ley 32/2006, de 18 de octubre, reguladora de la subcontratación en el sector de la construcción". 
sentada por el Grupo Parlamentario Socialista en el Congreso ${ }^{34}$ - advirtió que lo dispuesto en el art. 15 ET, apartados 1.a) y 5, y en el art. 49.1.c) ET se entendía sin perjuicio de lo que se establecía o pudiera establecerse sobre la regulación del contrato fijo de obra en la negociación colectiva de conformidad con la DA $3^{a}$ LSC $^{35}$; una redacción que parecía dar plena cobertura legal a la regulación convencional ${ }^{36}$ y que fue finalmente incorporada en la DA $3^{a}$ del propio Estatuto.

\subsection{El contrato fijo de obra en el sector de la construcción, ¿Un mecanismo de estabilidad en el empleo?}

Originariamente, el contrato fijo de obra representaba un importante mecanismo de estabilidad en el empleo en el sector de la construcción. En primer lugar, porque el personal que había prestado servicios en diferentes centros de trabajo adquiría la condición de indefinido por el mero transcurso del tiempo, sin más condicionamientos. En segundo lugar, porque el personal que había trabajado en una única obra de larga duración debía ser reubicado -al término de ésta- en otra de las obras que estuviera ejecutando la empresa, siempre y cuando, obviamente, existiese vacante en la misma.

La regulación convencional inicial, supuso un retroceso importante, hasta el punto de que la doctrina llegó a afirmar que lo único que quedaba de semejanza con la ordenanza era el nombre del contrato ${ }^{37}$. Se amplió a tres años el período de tiempo que debía transcurrir para que el trabajador adquiriera la condición de fijo de plantilla y se suprimió tanto la obligación de la empresa de reubicar al trabajador en una nueva obra, como la de notificar el cese a los representantes de los trabajadores. No obstante, el contrato fijo de obra seguía favoreciendo la estabilidad en el empleo, en la medida en que ponía un límite a la concatenación de contratos temporales.

Ahora bien, tras la modificación del art. 15 ET por las leyes 43/2006 y 35/2010, la limitación de la contratación temporal se hizo extensiva a todos los sectores de actividad, por lo que la regulación convencional perdió su carácter privilegiado. Es más, la regulación convencional posterior a estas reformas ha situado a los trabajadores del sector de la construcción en peor situación que el resto, en la medida en que ha pretendido impedir la aplicación de las garantías previstas en el precepto estatutario.

Precisamente por ello, parte de la doctrina laboralista ya advirtió que los agentes sociales no estaban favoreciendo la estabilidad en el empleo en el sector de la construcción ${ }^{38}$. Y de hecho, en la sentencia de 24-6-2021, el Tribunal de la Unión Europea alertó que, sin perjuicio de las comprobaciones que correspondiese efectuar al magistrado español, el art. 24 del convenio colectivo sectorial entraña un riesgo real de provocar una utilización abusiva de este tipo de contratos.

\footnotetext{
${ }^{34}$ BOCG 27-7-2010, núm. 81-8.

35 Como informa LUJÁN ALCARÁZ, José. "El contrato fijo de obra del sector de la construcción en la reforma de 2010", Revista Doctrinal Aranzadi Social, 2010, núm. 12, "la promulgación del RDLey 10/2010 fue muy contestada por la patronal del sector de la construcción al entenderse que en la práctica limitaba severamente las posibilidades de utilización futura del contrato".

${ }^{36}$ Según GOERLICH PESET, José María. "La reforma de la contratación temporal en el Real Decreto-Ley 10/2010". En: GARCÍA-PERROTE ESTARTÍN, Ignacio y MERCADER UGUINA, Jesús R. (dirs). La reforma laboral 2010. Aspectos prácticos. Valladolid: Lex Nova, 2010, p. 49, la DA 1" RDLey 10/2010 "parece ser una pantalla legislativa establecida para proteger este contrato por si acaso... Y con vocación de permanencia”.

${ }^{37}$ BARREIRO GONZÁLEZ, Germán; FERNÁNDEZ DOMÍNGUEZ, Juan José. “Contratación”. En: Valdés Dal-Ré, Fernando (dir.). Comentarios al convenio general de la construcción. Madrid: Fundación Anastasio de Gracia, 1993, p. 142.

${ }^{38}$ ARAGÓN GÓMEZ, Cristina. "El contrato fijo de obra en el nuevo convenio de la construcción. ¿¿Un mecanismo de estabilidad en el empleo?" Relaciones Laborales, 2008, núm. 2, pp. 21 a 48. GOERLICH PESET, José María. "La reforma de la contratación temporal en el Real Decreto-Ley 10/2010”. En: GARCÍA-PERROTE ESTARTÍN, Ignacio y MERCADER UGUINA, Jesús R. (dirs). La reforma laboral 2010. Aspectos prácticos. Valladolid: Lex Nova, 2010, p. 47 y RODRÍGUEZ ESCANCIANO, Susana. "Sostenibilidad laboral en el sector de la construcción: la estabilidad en el empleo como premisa”. Temas Laborales, 2020, núm. 152, p. 36.
} 


\section{El punto de llegada: El contrato indefinido adscrito a obra}

En respuesta a la resolución del Tribunal de Justicia de la Unión Europea ${ }^{39}$, el RDLey 32/2021 modifica la DA. $3^{\text {a }}$ LSC (que, como hemos visto, permitía la intervención de la negociación colectiva para adaptar el contrato por obra o servicio mediante fórmulas que garantizaran mayor estabilidad en el empleo de los trabajadores). En virtud de la nueva redacción del precepto, el contrato de un trabajador del sector de la construcción adscrito a una obra sería, en principio, indefinido. $Y$, ante la finalización de la obra, la empresa tendría la obligación de ofrecer al trabajador una propuesta de recolocación, aunque eso supusiese el desarrollo de un previo proceso de formación.

Antes de ahondar en el régimen jurídico de este contrato, conviene clarificar cuál es su concreto alcance. Desde un punto de vista objetivo, únicamente se aplica a las empresas del sector de la construcción "teniendo en cuenta las actividades establecidas en el ámbito funcional del convenio general" correspondiente al sector ${ }^{40}$. De otro lado, desde un punto de vista subjetivo, esta modalidad contractual solo alcanza a los trabajadores "adscritos a obra" es decir, "aquellos que tengan por objeto tareas o servicios cuya finalidad y resultado estén vinculados a obras de la construcción". De esta forma, quedarían al margen los trabajadores del sector de la construcción que formen parte del personal de estructura.

Concretado el ámbito de aplicación del precepto, podemos abordar su contenido. Como ya adelantamos, el legislador impone a la empresa la obligación de realizar al trabajador una propuesta de recolocación. Pues bien, este deber se activa ante la finalización de la obra, entendiendo por tal: a) "Ia terminación real, verificable y efectiva de los trabajos desarrollados" por la persona trabajadora; b) la disminución real del volumen de obra por la realización paulatina de las correspondientes unidades de ejecución debidamente acreditada; y c) una paralización, definitiva o temporal, de entidad suficiente de una obra por causa imprevisible para la empresa y ajena a su voluntad. De esta forma se incorporan al tenor de la DA. $3^{\text {a }}$ LSC, como causas justificativas de novación contractual, las previas causas de extinción del contrato fijo de obra que relacionaba el convenio colectivo ${ }^{41}$.

La finalización de la obra debe ser puesta en conocimiento de la representación legal de las personas trabajadoras, si la hubiere, así como de la comisión paritaria del convenio colectivo de aplicación o, en su defecto, de los sindicatos representativos del sector, con cinco días de antelación a su efectividad.

De concurrir alguna de las anteriores causas, la empresa debe ofrecer al trabajador afectado una propuesta de recolocación. Esta propuesta se debe realizar con 15 días de antelación a la finalización de su trabajo en la obra de origen y se debe formalizar por escrito mediante una cláusula que se anexa al contrato de trabajo. En ella se ha de precisar la ubicación de la nueva obra, la fecha de incorporación a la misma y las acciones formativas exigibles para ocupar el nuevo puesto.

A este respecto, conviene aclarar que el proceso de formación correrá siempre por cuenta de la empresa y podrá realizarse con antelación a la finalización de la obra. Por lo tanto, es posible que el tiempo de trabajo efectivo se simultanee con un tiempo de formación. Pues bien, en caso de que eso ocurra, debemos tener presente que el tiempo dedicado a "las acciones formativas exigibles para ocupar el nuevo puesto" debe computarse dentro de la jornada laboral ${ }^{42}$, por lo que la empresa

\footnotetext{
${ }^{39}$ Aunque no se haga ninguna referencia a esta sentencia en la Exposición de Motivos.

${ }^{40}$ Según el art. 3 del VI CGSC, se consideran actividades propias del sector de la construcción: a) Las dedicadas a la construcción y obras públicas; b) La conservación y mantenimiento de infraestructuras; c) Canteras, areneras, graveras y la explotación de tierras industriales; d) Embarcaciones, artefactos flotantes y ferrocarriles auxiliares de obras y puertos; y c) El comercio de la construcción mayoritario y exclusivista. Además, el propio convenio relaciona en su anexo I las actividades que integran el campo de aplicación del convenio; si bien, aclara que lo hace "a titulo enunciativo y no exhaustivo".

${ }^{41}$ Como con acierto advierte NOGUEIRA GUASTAVINO, Magdalena. "En búsqueda de la estabilidad perdida: la reforma de los fijos discontinuos y del contrato "fijo" de obra en el sector de la construcción”. Almacén de Derecho, 10-1-2022, https://almacendederecho.org.

${ }^{42}$ SSTS 11-12-2017, Ro 265/2016 y STS 29-4-2021, Ro 2688/2018, entre otras.
} 
deberá implantar las adaptaciones que sean precisas para garantizar al trabajador el debido tiempo de descanso ${ }^{43}$.

De otro lado, la DA. $3^{\text {a }}$ LSC advierte que el proceso de formación se puede impartir directamente por la empresa o desarrollarse a través de una entidad especializada, siendo preferente la formación que imparta la Fundación Laboral de la Construcción con cargo a las cuotas empresariales. Lo que no aclara el legislador en el alcance de este concreto deber de formación. A tal efecto, se remite a la negociación colectiva de ámbito estatal del sector de la construcción que será la que determine "los requisitos de acceso, duración y modalidades de formación adecuadas, según las cualificaciones requeridas para cada puesto, nivel, función y grupo profesional".

Pues bien, la principal particularidad de este contrato "indefinido adscrito a obra" es que puede extinguirse (además de por las causas previstas en el Estatuto de los Trabajadores) por lo que el legislador denomina "motivos inherentes a la persona trabajadora", entendiendo por tales las siguientes:

- Que el trabajador expresamente rechace la propuesta de recolocación en el plazo de siete días desde que tenga conocimiento de la comunicación empresarial o que no conteste dentro de ese período, pues se entiende que la falta de contestación equivale a un rechazo de la propuesta.

- Que la cualificación del trabajador no resulte adecuada a la necesidad de la empresa en las nuevas obras, "incluso tras un proceso de formación o recualificación". La verdad es que no queda muy claro a qué supuesto se está refiriendo el legislador: ¿a qué la recualifiacción en la práctica no sea viable? ¿a que el trabajador no haya superado satisfactoriamente el curso de formación? Porque si la causa de la falta de adecuación entre la cualificación del profesional y las necesidades de la empresa radica en las carencias del proceso formativo, difícilmente se puede sostener que estamos ante motivos inherentes a la persona trabajadora.

- Que exista un exceso de personas con esa concreta cualificación y que ello impida la integración del trabajador en las nuevas obras. Y, a tal efecto, la negociación colectiva de ámbito estatal del sector deberá precisar cuáles son los criterios de prioridad o permanencia que deben operar en caso de concurrir este motivo en varias personas trabajadoras de forma simultánea en relación con la misma obra.

- Y, por último, que no exista una nueva obra en esa misma provincia acorde a la cualificación profesional del trabajador o acorde a su posible recualificación.

Salvo en el primer supuesto, la empresa deberá notificar la extinción del contrato al trabajador afectado, preavisándole con quince días. Y, en todo caso, deberá hacer partícipe a la representación legal de esta decisión extintiva con una antelación de siete días a su efectividad.

Según prevé la reforma, la extinción del contrato indefinido por cualquiera de estos cuatro motivos tiene dos consecuencias: En primer lugar, el trabajador tiene derecho a una indemnización del 7\% de los conceptos salariales establecidos en las tablas del convenio colectivo que resulte de aplicación y que hayan sido devengados durante la vigencia del contrato "o la superior establecida por el Convenio General del Sector de la Construcción" (DA 3a.6 LSC). En segundo lugar, el trabajador se considera en situación legal de desempleo y tiene, en el caso de cumplir los restantes requisitos, derecho al paro. A tal efecto, el art. 3.Tres RDLey 32/2021 modifica el art. 267 LGSS y, en virtud de su nueva redacción, se encuentran en situación legal de desempleo los trabajadores cuyo contrato de trabajo se extinga "por motivos inherentes a la persona trabajadora regulada en la

\footnotetext{
${ }^{43}$ STJUE 28-10-2021 (C-909/19).
} 
disposición adicional tercera de la Ley 32/2006, de 18 de octubre, reguladora de la subcontratación en el Sector de la Construcción".

\section{Conclusión}

En definitiva, el previo contrato fijo de obra se extinguía ante la ausencia de una nueva obra en la misma provincia. Y el nuevo contrato indefinido adscrito a obra también y con la misma indemnización. El previo contrato fijo de obra se resolvía si el trabajador no estaba conforme con el nuevo destino. Y el nuevo contrato indefinido adscrito a obra también y con los mismos efectos. Tras la extinción del contrato fijo de obra, el trabajador tenía derecho a desempleo. Y tras la extinción del nuevo contrato indefinido adscrito a obra también y en iguales términos. ¿Qué ha cambiado entonces? Nada, salvo el nombre. En síntesis, como con acierto afirma la profesora Vicente Palacio, el calificativo "indefinido" es meramente estético o decorativo ${ }^{44}$.

No obstante, es verdad que, en la práctica, sí se constatan dos mejoras con respecto a la regulación anterior. La primera mejora se va a concretar en un incremento del neto de la nómina de aquellos trabajadores que se vean afectados por un desplazamiento a un municipio distinto del lugar habitual de trabajo. El convenio colectivo del sector de la construcción prevé la compensación de los gastos de alojamiento y de manutención, así como de los gastos de locomoción ante situaciones de desplazamiento con motivo de un cambio de obra. Pues bien, cuando dicho cambio de centro afectaba a un trabajador "fijo de obra", la Inspección de Trabajo y Seguridad Social ${ }^{45}$ y la Dirección General de Tributos ${ }^{46}$ entendían que estos importes debían computarse en la base de cotización y en la base de retención por IRPF, por cuanto estábamos ante diferentes contratos (aunque se tramitaran como uno solo) y cada uno de ellos estaba adscrito a un centro de trabajo diferente. No había un centro de trabajo de origen y un centro de trabajo de destino, por lo que la adscripción del trabajador a una nueva obra no suponía un desplazamiento. Y de ahí que las "dietas" no tuvieran naturaleza extrasalarial (si no hay desplazamiento, no hay gastos que compensar) y debieran computarse íntegramente.

Sin embargo, si estos mismos gastos se abonan a un trabajador "indefinido adscrito a obra" y no superan el importe legalmente establecido ${ }^{47}$, sí quedarían exentos de tributación y de cotización en virtud de lo dispuesto en los arts. 17.1.d) Ley 35/2006 ${ }^{48}$ y 23.2.A) RD 2064/1995 ${ }^{49}$, respectivamente, pues al tratarse de un único contrato sí se constataría un centro de trabajo origen y un centro de destino, o dicho en otros términos, sí existiría un desplazamiento y las dietas no perderían su naturaleza de suplido. A este respecto, la Dirección General de Tributos consideró exentas de gravamen las dietas por manutención por causa de desplazamiento del trabajador fijo de plantilla a un municipio distinto de su lugar de trabajo habitual y del que constituya su residencia,

${ }^{44}$ VICENTE PALACIO, Arántzazu. Contrato para obra o servicio determinado: Descanse en paz. ¡Viva el contrato fijo discontinuo! Disponible en Internet: https://www.aedtss.com/wp-content/uploads/2022/01/OBITUARIO-ARANTCHA.pdf

${ }^{45}$ Ministerio de Trabajo y Asuntos Sociales. Dirección General de la Inspección de Trabajo y Seguridad Social. Criterio técnico 40/2015 sobre cotización por dietas y gastos de desplazamiento en el sector de la construcción de los trabajadores fijos de obra.

${ }^{46}$ Consultas Vinculantes de 13-8-2007, núm. V1777-07, 22-12-2008, núm. V2468-08 y 13-9-2018, núm. V2493-18.

${ }^{47}$ En el art. 9 Real Decreto 439/2007, de 30 de marzo, por el que se aprueba el Reglamento del Impuesto sobre la Renta de las Personas Físicas y se modifica el Reglamento de Planes y Fondos de Pensiones, aprobado por Real Decreto 304/2004, de 20 de febrero (BOE 31-3-2007, núm. 78).

${ }^{48}$ Ley 35/2006, de 28 de noviembre, del Impuesto sobre la Renta de las Personas Físicas y de modificación parcial de las leyes de los Impuestos sobre Sociedades, sobre la Renta de no Residentes y sobre el Patrimonio (BOE 29-11-2006, núm. 285).

${ }_{49}^{4}$ Real Decreto 2064/1995, de 22 de diciembre, por el que se aprueba el Reglamento General sobre Cotización y Liquidación de otros Derechos de la Seguridad Social (BOE 25-1-1996, núm. 22). 
siempre que cumplieran los requisitos formales y cuantitativos establecidos por la ley y su concreto desarrollo reglamentario ${ }^{50}$.

La segunda mejora con respecto a la regulación convencional radica en que se impone a la empresa la obligación de ofrecer al trabajador una recolocación en el caso de que tenga una nueva obra en la provincia para la cual se requieran trabajadores de su cualificación real o de su cualificación posible. ¿Pero estamos ante una mejora significativa? Si estuviéramos ante un trabajador indefinido ordinario, ¿esta propuesta de recolocación no se desprendería naturalmente del derecho básico a la ocupación efectiva?

Como se aprecia de lo anteriormente expuesto, no estamos ante cambios especialmente importantes. Y lo más preocupante es que el legislador, con la reforma, introduce en el ordenamiento jurídico algunas diferencias de trato que tienen difícil justificación.

En primer lugar, el legislador califica de motivos de extinción "inherentes a la persona del trabajador" causas claramente organizativas o productivas (como es el exceso de operarios con una determinada cualificación o como es la falta de una nueva obra en la misma provincia). Sin embargo, prevé un régimen de extinción particularizado para estos supuestos, al margen del establecido en el Estatuto de los Trabajadores, lo que plantea interrogantes importantes. Está claro que, a efectos indemnizatorios, el contrato indefinido adscrito a obra prevé una compensación superior a la establecida en el precepto estatutario (pues ya hemos visto que un 7\% de las retribuciones devengadas durante la vigencia del contrato equivale a pagar unos 25 días de salario por año de servicio; una indemnización superior por tanto a los 20 días que prevé el Estatuto). ¿Pero qué ocurre con el resto de las garantías de los arts. 51 y 52 ET? Si la indemnización no se entrega de forma simultánea a la comunicación de la extinción, ¿conllevaría la improcedencia del cese? ¿Los trabajadores que estén ejerciendo derechos de conciliación de la vida laboral y familiar tendrían una tutela reforzada frente a la decisión extintiva de la empresa? ${ }^{51}$ ¿Se computan estas extinciones a efectos de los umbrales del despido colectivo? ¿Es necesario un previo período de consultas con la representación legal? Parece que la respuesta a todas estas preguntas es negativa, pues no estamos -en palabras del legislador- ante causas económicas, técnicas, organizativas o de producción, sino ante causas "inherentes a la persona del trabajador", lo que en algunos supuestos -como hemos visto- es más que discutible. Es más, por si quedara algún resquicio de duda, el propio legislador advierte que este régimen extintivo particular resulta aplicable "con independencia del número de personas trabajadoras afectadas".

Es cierto que la DA $3^{\text {a }}$ LSC, en su nueva redacción, impone a la empresa la obligación de preavisar al trabajador afectado con 15 días de antelación, así como de notificar a la representación legal de las personas trabajadoras la extinción del contrato con una antelación de siete días a su efectividad. Y además se habilita a la negociación colectiva para fijar los criterios de permanencia en la empresa. Pero, tales medidas, "están lejos de las obligaciones de información y consulta exigidas por la Directiva 98/59'52.

En definitiva, con la reforma, se genera una diferencia de trato entre los trabajadores indefinidos ordinarios y los trabajadores indefinidos adscritos a obra, cuya justificación no parece ser otra

\footnotetext{
${ }^{50}$ Consultas Vinculantes de la DGT de 13-8-2007, núm. V1777-07, 22-12-2008, núm. V2468-08 y 13-9-2018, núm. V2493-18.

${ }^{51} \mathrm{Y}$ no hago expresa alusión a las mujeres embarazadas por cuanto será difícil encontrar una mujer en situación de gravidez "adscrita a obra", teniendo en cuenta que estamos ante un sector de actividad claramente masculinizado. Según los datos de la Encuesta de Población Activa, correspondientes al cuarto trimestre del año 2021, un 89,87\% de los profesionales ocupados en el sector de la construcción son hombres (INE. Encuesta de Población Activa. Ocupados por sexo y rama de actividad. Valores absolutos y porcentajes respecto del total de cada sexo. 2021T4).

${ }^{52}$ Como con acierto advierte BELTRÁN DE HEREDIA, Ignasi. "RDLey 32/2921 y el contrato indefinido adscrito a obra (Ley 32/2006): dudas de constitucionalidad y motivos para una (eventual) cuestión prejudicial". Una mirada crítica a las relaciones laborales, 24-1-2022. https://ignasibeltran.com
} 
que lograr la aquiescencia de la patronal y de los sindicatos con el fin de "rebautizar" el contrato para que, siendo lo mismo que era, no compute a efectos estadísticos.

En segundo lugar, resulta igualmente un contrasentido que se reconozca la prestación por desempleo al trabajador adscrito a obra que desestima la propuesta de recolocación de la empresa. Como bien sabemos, la prestación por desempleo se dirige a proteger a quienes "pudiendo y queriendo trabajar, pierdan su empleo o vean reducida su jornada ordinaria de trabajo" (art. 267 LGSS). Y este elemento delimitador de la situación protegida se concreta en la necesidad de que la pérdida del trabajo no haya sido a consecuencia de una decisión libremente adoptada por el trabajador. Es más, esta voluntad de trabajar no sólo ha de darse en el momento del cese, sino también durante todo el período de percepción del subsidio. Y de ahí que se exija la inscripción formal del beneficiario como demandante de empleo en el servicio público competente [arts. 266.e) y 268 LGSS] y de que se obligue al beneficiario a suscribir el compromiso de actividad [arts. 266.c) y 300 LGSS]. En definitiva, es preciso que el cese no haya sido debido a actos imputables al trabajador (involuntariedad originaria) y que el beneficiario muestre una voluntad o disposición para incorporarse de nuevo al mercado de trabajo a lo largo del tiempo que dura la prestación (involuntariedad sucesiva).

Precisamente por ello, la extinción de un contrato formativo o de un contrato de duración determinada por la expiración del tiempo convenido no se considera situación legal de desempleo cuando la resolución obedezca a la denuncia del propio trabajador [art. 267.1.a).6 $6^{\circ}$ LGSS]. Y, con base en esta misma lógica, tampoco encuentra cabida en este concepto la resolución del contrato durante el período de prueba a instancia del empleado [art. 267.1.a).7º LGSS]. De ahí que no tenga sentido que se incluya dentro del ámbito de protección de la prestación por desempleo al trabajador indefinido adscrito a obra que rechaza una propuesta recolocación de su empresario, sin exigir ningún tipo de causa.

Es cierto que el legislador considera situación legal de desempleo varios supuestos de resolución voluntaria del contrato de trabajo. Pero se trata de las causas de extinción previstas en los arts. 40.1, 41.3 y 50 ET. Y no podemos olvidar que, aun tratándose de situaciones en las que concurre la voluntad extintiva de la persona trabajadora, la misma se encuentra provocada por una previa decisión empresarial que ha ocasionado un daño. Estamos así ante un cambio de centro de trabajo que conlleva un correlativo cambio de residencia ${ }^{53}$, ante una modificación sustancial de las condiciones de trabajo que causa un perjuicio al trabajador que puede ser probado (art. $41.3 \mathrm{ET})^{54}$ o que menoscaba su dignidad [art. 50.1.a) ET] o ante un incumplimiento grave de las obligaciones del empresario, incluyendo entre ellas la falta de pago o los retrasos continuados en el abono del salario pactado [art. 50.1, apartados b) y c) ET]. Sin embargo, el trabajador indefinido adscrito a obra que renuncia a una propuesta de recolocación tiene derecho al desempleo en todo caso, sin necesidad de sufrir ningún perjuicio. No tiene que alegar causa alguna. De hecho, ni siquiera tiene por qué contestar a la propuesta de recolocación empresarial, pues ya hemos visto que la ausencia de contestación se equipara a un rechazo.

${ }^{53}$ Como nos recuerda el Tribunal Supremo en su sentencia de 15-6-2021, Ro 3696/2018, un cambio de centro de trabajo sin incidencia en la residencia constituye una modificación accidental de las condiciones de trabajo que se encuadra dentro de la potestad organizativa del empresario. Por ello, tales cambios quedan amparados por el ordinario poder de dirección del empresario y no se hallan sujetos a procedimiento o justificación algunos. Y tampoco se otorga al trabajador afectado el derecho extintivo que sí se atribuye en el art. $40 \mathrm{ET}$.

${ }^{54} \mathrm{Si}$ en los traslados forzosos se sobreentiende el perjuicio, en las modificaciones sustanciales de las condiciones de trabajo el perjuicio no se presume, sino que debe ser probado por el propio trabajador afectado. Es más, el Tribunal Supremo entiende que el perjuicio debe ser relevante, pues no sería razonable, ni proporcional, sancionar con la rescisión contractual indemnizada cualquier modificación que ocasionara un perjuicio mínimo, al ser ello contrario al espíritu de la norma que persigue la supervivencia de la em-

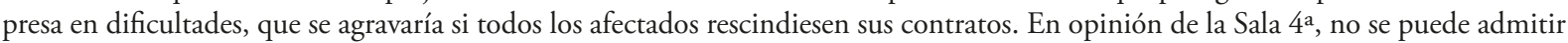
la resolución indemnizada de forma automática, pues si el legislador hubiera querido que toda modificación sustancial comportara el derecho a que las personas afectadas pudieran extinguir su contrato de trabajo con derecho al percibo de la indemnización y acceder a la situación legal de desempleo, debiera haber redactado el art. 41.3 ET en otros términos (STS 23-7-2020, Ro 822/2018). 
No parece que tenga mucha lógica considerar en situación legal de desempleo a quien rechaza una oferta de recolocación de su empresa, cuando, precisamente, uno de los requisitos de acceso y mantenimiento de la prestación es la suscripción del compromiso de actividad mediante el cual el beneficiario se obliga a buscar activamente empleo, a participar en acciones de formación o reconversión profesional, y a aceptar una colocación adecuada. Y esta adecuación se perfila a través de tres perspectivas o criterios de delimitación distintos: a) el criterio funcional; b) el criterio territorial o topográfico; y c) el criterio económico o retributivo ${ }^{55}$. Pues bien, ateniéndonos al primero de ellos, se entiende que una oferta es adecuada cuando se refiera a la profesión demandada por el trabajador y también aquella que se corresponda con su profesional habitual o que se ajuste a sus aptitudes físicas o formativas. No obstante, el art. 301 LGSS aclara a continuación: "En todo caso, se entenderá por colocación adecuada la coincidente con la última actividad laboral desempeñada siempre que su duración hubiese sido igual o superior a tres meses". Además, transcurrido un ańo de percepción ininterrumpida de la prestación también podrán ser consideradas adecuadas otras colocaciones que a juicio del servicio público de empleo puedan ser ejercidas por el trabajador. Partiendo de lo expuesto, me pregunto si tiene sentido permitir la resolución de un contrato con motivo de un cambio de obra e incluir dicha situación en el ámbito de protección de la prestación por desempleo, para luego exigir al trabajador que acepte un nuevo puesto de trabajo en el sector de la construcción. Quizá sería necesario partir de una visión más integral y coordinar la regulación sustantiva y la de Seguridad Social, de forma que únicamente se tenga derecho a la prestación por desempleo en los supuestos en los que la propuesta de recolocación no se considere adecuada, con base en los criterios relacionados en el art. 301 LGSS.

\section{Régimen transitorio}

De conformidad con la DT $3^{\text {a }}$ RDLey 32/2021, los contratos fijos de obra suscritos antes del 3112-2021 se mantienen vigentes tras la reforma y se regirán por los términos recogidos en el art. 24 del VI Convenio estatal del sector de la construcción (DT $3^{\mathrm{a}}$ ).

Por su parte, los contratos para obra y servicio determinado (y el contrato fijo de obra lo es) celebrados entre el 31-12-2021 y el 30-32022, se regirán por la normativa legal o convencional vigente en la fecha en que se han concertado, pero su duración no podrá ser superior a seis meses (DT 4a)].

${ }^{55}$ DESDENTADO BONETE, Aurelio y MERCADER UGUINA, Jesús R. El desempleo como situación protegida (un estudio sobre los problemas de acceso a la protección en el nivel contributivo y en el asistencial). Madrid: Civitas, 1996, pp. 43 a 49. 